\title{
Phase formation, structure and dielectric properties of ceramics $\left(\mathrm{Na}_{0.5} \mathrm{Bi}_{0.5}\right) \mathrm{TiO}_{3}-\left(\mathrm{K}_{0.5} \mathrm{Na}_{0.5}\right) \mathrm{NbO}_{3}-\mathrm{BiFeO}_{3}{ }^{*}$
}

\author{
G. M. Kaleva ${ }^{\dagger}$, A. V. Mosunov ${ }^{\dagger}$, N. V. Sadovskaya ${ }^{\dagger}$, \\ E. D. Politova ${ }^{\dagger, \S}$ and S. Yu. Stefanovich ${ }^{\dagger, \dagger}$ \\ ${ }^{\dagger}$ L. Ya. Karpov Institute of Physical Chemistry \\ Obukha s.-st., 3-1/12, Moscow 105064, Russia \\ Lomonosov Moscow State University \\ Leninskie Gory, 1, 119992, Moscow, Russia \\ \$politova@cc.nifhi.ac.ru
}

Received 3 November 2015; Revised 11 December 2015; Accepted 6 February 2016; Published 11 April 2016

\begin{abstract}
Influence of $\mathrm{BiFeO}_{3}(\mathrm{BF})$ on phase formation, unit cell parameters, microstructure, dielectric and ferroelectric properties of solid solutions close to the morphotropic phase boundary in the $\left(\mathrm{Na}_{0.5} \mathrm{Bi}_{0.5}\right) \mathrm{TiO}_{3}-\left(\mathrm{K}_{0.5} \mathrm{Na}_{0.5}\right) \mathrm{NbO}_{3}$ system additionally modified by the low-melting $\mathrm{KCl}$ additives has been studied. The formation of pure perovskite structure samples decrease in the unit cell parameters and increase in the $T_{C}$ value stimulated by the $\mathrm{BF}$ addition have been revealed. It was proved that modification of compositions by small amounts of the $\mathrm{BF}$ and $\mathrm{KCl}$ additives leads to improvement of dielectric parameters.
\end{abstract}

Keywords: $\left(\mathrm{Na}_{0.5} \mathrm{Bi}_{0.5}\right) \mathrm{TiO}_{3}$, $\left(\mathrm{K}_{0.5} \mathrm{Na}_{0.5}\right) \mathrm{NbO}_{3} ; \mathrm{BiFeO}_{3} ; \mathrm{KCl}$; MPB; perovskite structure; microstructure; ferroelectric phase transitions.

\section{Introduction}

Piezoelectric materials are technologically important because of their application in various kinds of devices. They have also great potential for applications in new areas such as energy harvesting devices, magnetoelectric sensors, micromotors and high power transformers. Due to their excellent piezoelectric and ferroelectric properties, $\mathrm{PbZr}_{x} \mathrm{Ti}_{1-x} \mathrm{O}_{3}$ and other lead-based materials have been dominating in various applications in the past few decades. However, increasing concern about environment stimulates the development of new ecologically friendly piezoelectric materials. ${ }^{1-9}$ In spite of the extensive research carried out, properties of new leadfree piezoelectric materials cannot compete with those of the lead-containing ones still.

Ceramic solid solutions with perovskite-type structure based on bismuth-sodium titanate $\left(\mathrm{Bi}_{0.5} \mathrm{Na}_{0.5}\right) \mathrm{TiO}_{3}$ (BNT) and potassium-sodium niobate $\left(\mathrm{K}_{0.5} \mathrm{Na}_{0.5}\right) \mathrm{NbO}_{3}(\mathrm{KNN})$ are considered among the most promising and intensively studied materials. ${ }^{1-17}$ At room temperature BNT has rhombohedral $R 3 \mathrm{c}$ symmetry. It gradually transforms to the tetragonal phase in a broad temperature range between $\sim 500$ and $700 \mathrm{~K}$ and then to a cubic phase at $\sim 800 \mathrm{~K}$. BNT has rather large remnant polarization $P_{r} \sim 38 \mu \mathrm{C} / \mathrm{cm}^{2}$ and high Curie temperature $T_{C} \sim 600 \mathrm{~K}$, however, high coercive field $E_{C}>37 \mathrm{kV} / \mathrm{cm}$ comprises its disadvantage. ${ }^{10-14} \mathrm{KNN}$ has an orthorhombic perovskite crystal structure at room temperature and exhibits two-phase transitions from ferroelectric orthorhombic to ferroelectric tetragonal phase at $\sim 473 \mathrm{~K}$ and then from tetragonal to paraelectric cubic one at $\sim 700 \mathrm{~K} .{ }^{15-22}$ At room temperature piezoelectric coefficient $d_{33}=80 \mathrm{pC} / \mathrm{N}$ was received. ${ }^{14-17}$

Rather promising results for improving piezoelectric properties were obtained for solid solutions in the BNT-KNN systems close to the morphotropic phase boundaries (MPB). ${ }^{19-26}$ In the BNT-rich system a rhombohedral to tetragonal MPB at $\sim 6-7.5 \mathrm{~mol} \% \mathrm{KNN}$ and the rhombohedral to pseudocubic MPB at 3-5 mol\% of KNN were reported. ${ }^{22,24}$ The reported values of piezoelectric properties in these systems are not optimized yet, and improvements may be reached by further modification of compositions in order to control intrinsic structural instabilities and extrinsic domain wall contributions. ${ }^{8}$

Bismuth ferrite $\mathrm{BiFeO}_{3}(\mathrm{BF})$ has a rhombohydral perovskite structure at room temperature and is characterized by very high $T_{C} \sim 1100 \mathrm{~K} .{ }^{12} \mathrm{So}$, the purpose of this work was to synthesize ceramic samples based on the compositions from MPB in the system BNT-KNN modified by BF and to study the influence of $\mathrm{BF}$ and $\mathrm{KCl}$ additives on phase formation, unit cell parameters, microstructure, dielectric and ferroelectric properties of solid solutions. It was expected that

\footnotetext{
*This paper is submitted to the 2nd Russia-China workshop on Dielectric and Ferroelectric Materials, Voronezh, Russia, 11-14 September 2015. This is an Open Access article published by World Scientific Publishing Company. It is distributed under the terms of the Creative Commons Attribution 4.0 (CC-BY) License. Further distribution of this work is permitted, provided the original work is properly cited.
} 
introduction of $\mathrm{BF}$ could increase the $T_{C}$ value, while the low-melting $\mathrm{KCl}$ additive could help to lower the sintering temperature of the ceramics and maintain their stoichiometry.

\section{Experimental Procedure}

Ceramic samples in the system $(1-y)\left[(1-x)\left(\mathrm{Na}_{0.5} \mathrm{Bi}_{0.5}\right) \mathrm{TiO}_{3}-\right.$ $\left.x\left(\mathrm{~K}_{0.5} \mathrm{Na}_{0.5}\right) \mathrm{NbO}_{3}\right]-y \mathrm{BiFeO}_{3}(=0.06,0.08,0.10 ; y=0.025$, $0.05,0.075,0.10)$ were prepared by the solid-state reaction method at $T_{1}=1073 \mathrm{~K}(5 \mathrm{~h})$ and $T_{2}=1413-1473 \mathrm{~K}(2 \mathrm{~h})$. Sodium carbonate $\mathrm{Na}_{2} \mathrm{CO}_{3}$ ("pure" grade), potassium carbonate $\mathrm{K}_{2} \mathrm{CO}_{3}$ ("analytical" grade) and oxides $\mathrm{Bi}_{2} \mathrm{O}_{3}$ ("pure" grade), $\mathrm{TiO}_{2}, \mathrm{Nb}_{2} \mathrm{O}_{5}, \mathrm{Fe}_{2} \mathrm{O}_{3}$ ("extra pure" grade) were used as starting materials. 5 wt. $\%$ of $\mathrm{KCl}$ ("pure" grade) with melting temperature of $\sim 1050 \mathrm{~K}$ were added after synthesis at $T_{1}$. The phase content and crystal structure parameters were studied using the X-ray diffraction method (DRON-3M with $\mathrm{Cu}_{K \alpha}$-beam). The microstructure of ceramic samples was examined by the Scanning Electron Microscopy (SEM) method (JEOL YSM-7401F equipped with a JEOL JED-2300

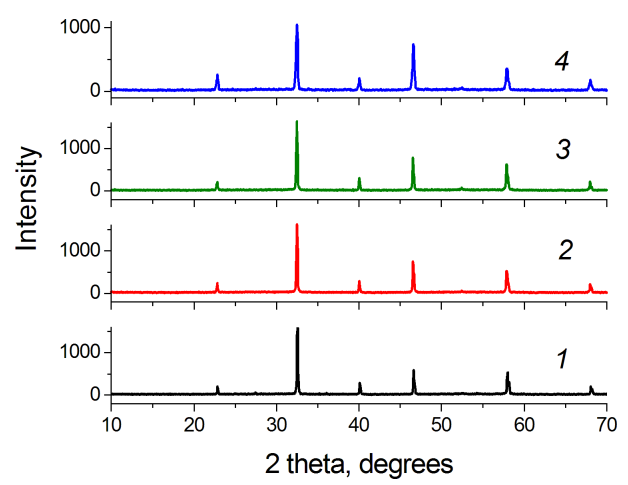

(a) energy dispersive X-ray spectrometer system). Spontaneous polarization was estimated using the Second Harmonic Generation method (SHG, Nd:YAG laser, $\lambda=1.064 \mu \mathrm{m}$ ). Dielectric properties were studied using the dielectric spectroscopy method (Agilent $4284 \mathrm{~A}, 1 \mathrm{~V}$ ) in the temperature range of $300-1000 \mathrm{~K}$ at frequencies $100 \mathrm{~Hz}-1 \mathrm{MHz}$.

\section{Results and Discussion}

According to the X-ray diffraction data, perovskite structure phase was formed at the calcination temperature $T_{1}=$ $1073 \mathrm{~K}$, though some amounts of impurity phases were registered as well. After sintering at temperatures of 1413$1473 \mathrm{~K}$ the amounts of the impurity phases were reduced, and single-phase samples were obtained at optimal temperature of 1443-1473 K (Fig. 1(a)). However, in samples with larger BF content $(y=0.08,0.10)$ small amounts of impurity phases $\mathrm{FeTi}_{2} \mathrm{O}_{5}$ and $\mathrm{Na}_{2} \mathrm{Ti}_{12} \mathrm{O}_{25}$ were registered (Fig. 1(b)).

Figure 2 demonstrates the displacements of the diffraction peaks with $h^{2}+k^{2}+l^{2}=4$ to smaller angles with $\mathrm{KNN}$ and

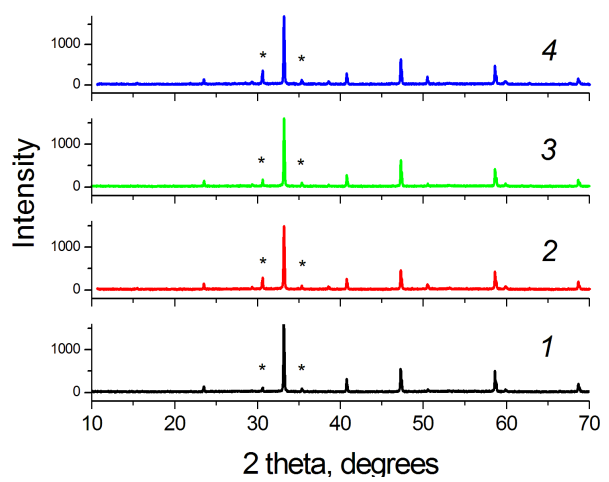

(b)

Fig. 1. The X-ray diffraction patterns of the samples $(1-y)\left[(1-x)\left(\mathrm{Na}_{0.5} \mathrm{Bi}_{0.5}\right) \mathrm{TiO}_{3}-x\left(\mathrm{~K}_{0.5} \mathrm{Na}_{0.5}\right) \mathrm{NbO}_{3}\right]-y \mathrm{BiFeO}$ : (a) With $x=0.06$, $y=0.025$ (1), 0.05 (2), 0.075 (3), 0.10 (4); (b) samples doped by 5 wt.\% of KCl with $x=0.08(1,2), 0.10(3,4), y=0.05(1,3), 0.075(2,4)$ sintered at $1443 \mathrm{~K}(\mathrm{a}, 1-4)$, at $1463 \mathrm{~K}(\mathrm{~b}, 1,3)$, at $1413 \mathrm{~K}(\mathrm{~b}, 2$ 4). Note: * marks peaks from admixture phases.

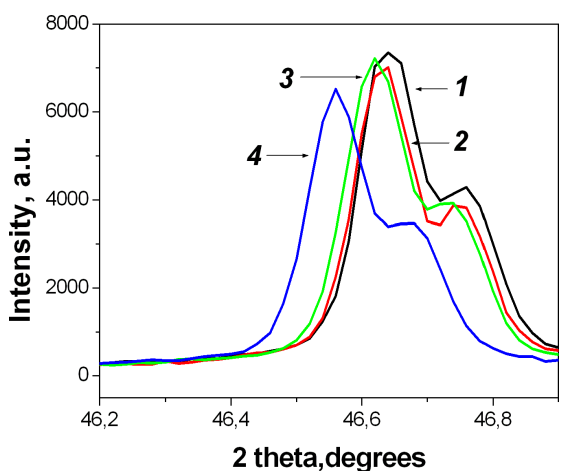

(a)

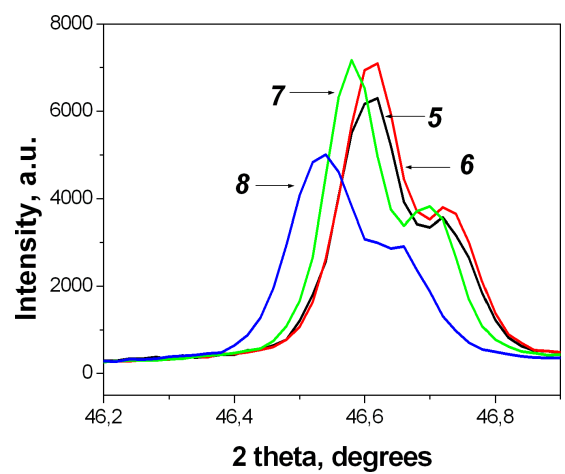

(b)

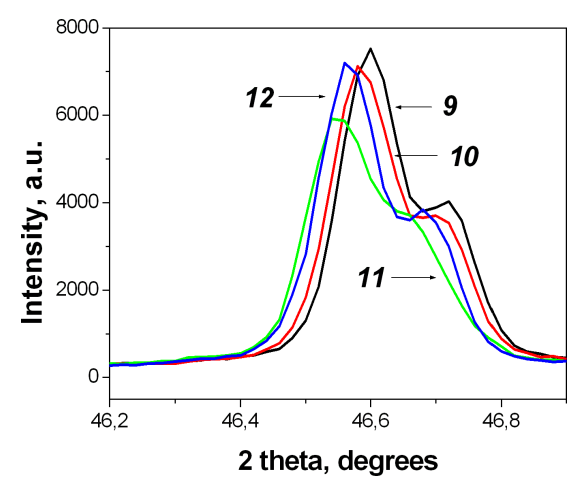

(c)

Fig. 2. Parts of the X-ray diffraction patterns showing peaks with $h^{2}+k^{2}+l^{2}=4$ for the samples $(1-y)\left[(1-x)\left(\mathrm{Na}_{0.5} \mathrm{Bi}_{0.5}\right) \mathrm{TiO}_{3}-x\right.$ $\left.\left(\mathrm{K}_{0.5} \mathrm{Na}_{0.5}\right) \mathrm{NbO}_{3}\right]-y \mathrm{BiFeO}_{3}$ with $x=0.06$ (a), (d), 0.08 (b), (e), 0.10 (c), (f); $y=0.025(1,5,9), 0.05(2,6,10), 0.075$ (3, 7,11$), 0.10$ (4, $8,12)$ doped with 5 wt. $\%$ of $\mathrm{KCl}(\mathrm{d})$, (e), (f) sintered at $1443 \mathrm{~K}(2 \mathrm{~h})$. 


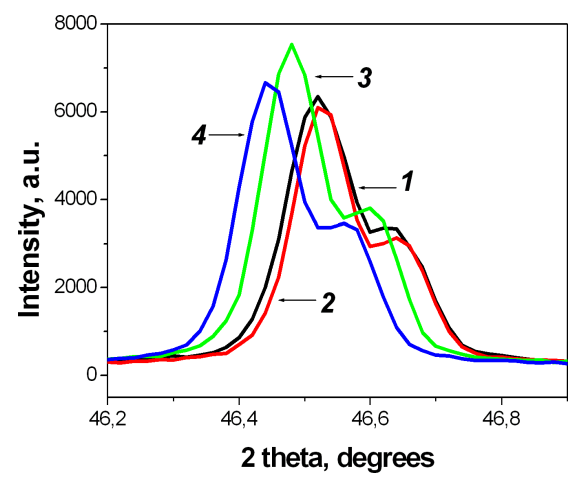

(d)

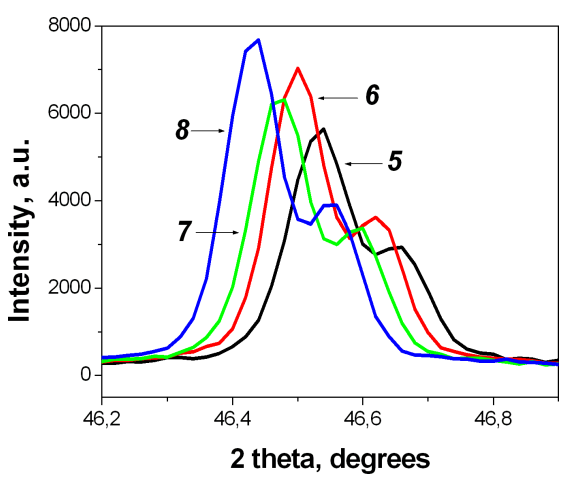

(e)

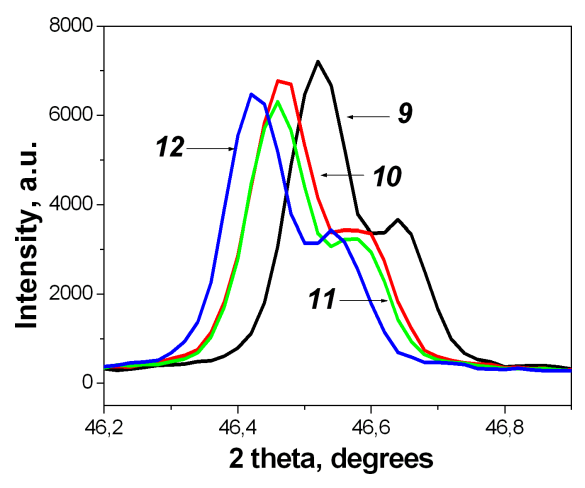

(f)

Fig. 2. (Continued)

$\mathrm{KCl}$ addition indicating to increase in the pseudocubic unit cell volume as a result of partial substitution of A-cations in the initial compositions by larger $\mathrm{K}^{1+}$ cations.

Microstructure of the samples was examined by the highresolution SEM method. All samples consisted of dense packed cubic grains with the size of $2-8 \mu \mathrm{m}$ (Fig. 3). Considerable decrease in grain sizes and improvement of density of ceramics was revealed for KCl-modified samples with $x=$ 0.08 and $y=0.10$ in comparison with unmodified samples. However, the formation of regions with larger grains of $\sim 10-15 \mu \mathrm{m}$ as well. Quantitative elemental analysis revealed deficiency up to 30 at. $\%$ of $\mathrm{K}^{1+}$-cations in some grains due to volatilization of alkali elements at high sintering temperatures $\sim 1473 \mathrm{~K}$.

Ceramic samples obtained were studied by the SHG method. The relative intensity of the SHG signal $q=I_{2 w} / I_{2 w}\left(\mathrm{SiO}_{2}\right)$ related to the spontaneous polarization $P_{s}$ as $q \sim P_{s}^{0.5}$ was measured in the range of 0.1-1.2. Such small $q$ values confirm that the samples may be characterized as anti- or ferrielectrics. It is worth noting that the initial $\mathrm{KNN}$ samples reveal good ferroelectric properties and are characterized by high values of the SHG signal up to $q \sim 7000$. So,

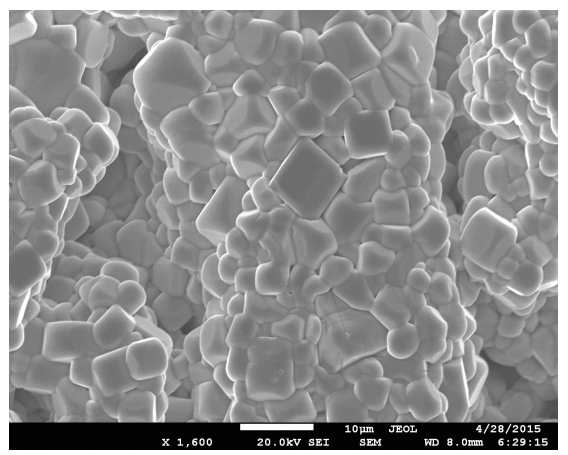

(a)

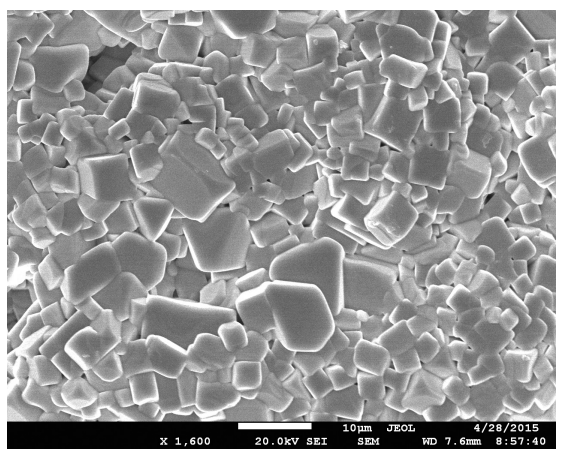

(d)

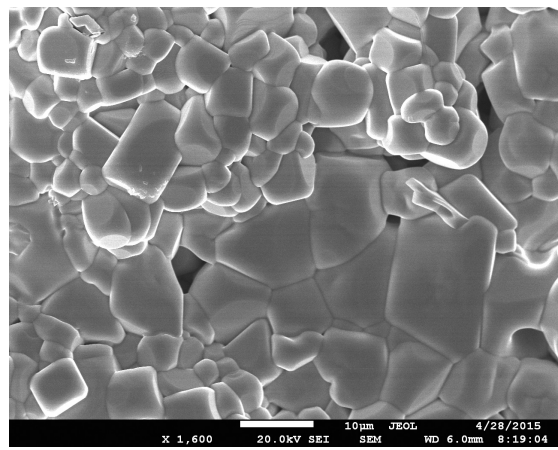

(b)

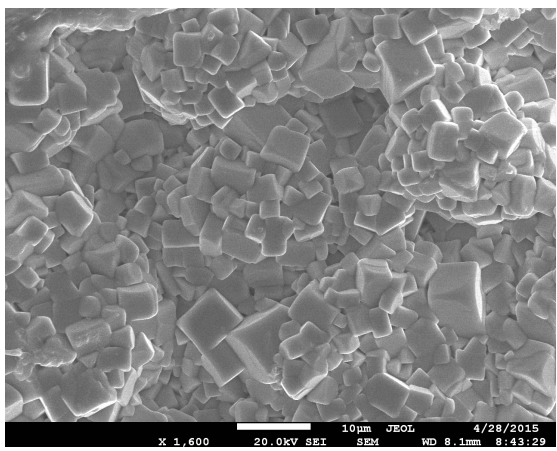

(e)

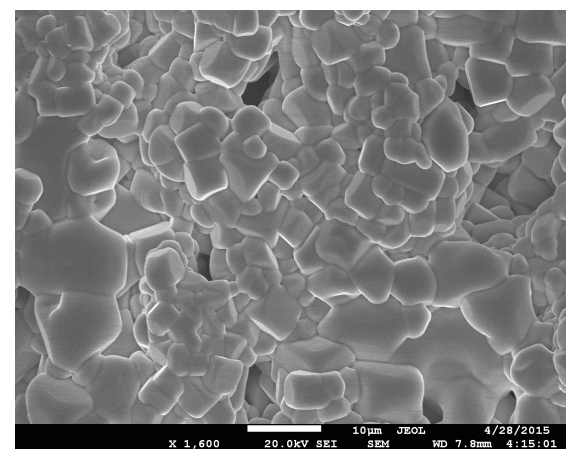

(c)

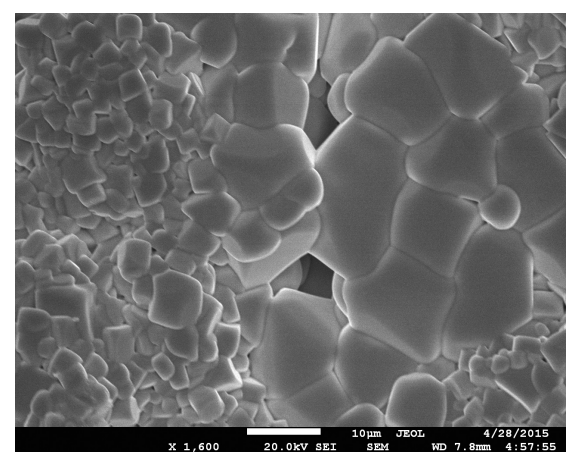

(f)

Fig. 3. Microstructure of the surface of the $(1-y)\left[(1-x)\left(\mathrm{Na}_{0.5} \mathrm{Bi}_{0.5}\right) \mathrm{TiO}_{3}-x\left(\mathrm{~K}_{0.5} \mathrm{Na}_{0.5}\right) \mathrm{NbO}_{3}\right]-y \mathrm{BiFeO}_{3}$ samples with $x=0.06$ (a), (b), 0.08 (c), (d), 0.10 (e), (f); with 5 wt.\% of $\mathrm{KCl}$ (b), (d), (f). Bars $-10 \mu \mathrm{m}$. 


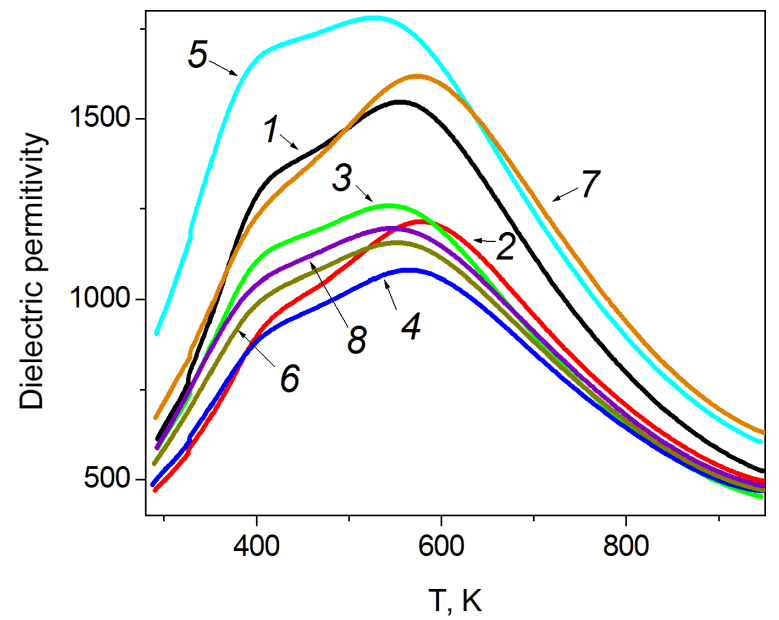

Fig. 4. Temperature dependences of dielectric permittivity $\varepsilon(T)$ of the samples $(1-y)\left[(1-x)\left(\mathrm{Na}_{0.5} \mathrm{Bi}_{0.5}\right) \mathrm{TiO}_{3}-x\left(\mathrm{~K}_{0.5} \mathrm{Na}_{0.5}\right) \mathrm{NbO}_{3}\right]-$ $y \mathrm{BiFeO}_{3}$ with $x=0.06(1,2), 0.08(3,4), 0.10(5,6,8), y=0.05(1$, $3,5), 0,10(2,4,6)$, sintered at $1473 \mathrm{~K}(1,3,5)$, at $1443 \mathrm{~K}(2,4,6)$; samples doped by $\mathrm{KCl}$ with $x=0.06$ (7), $0.10(8), y=0.10(7,8)$ sintered at $1443 \mathrm{~K}$. Frequency of measurements $f=1 \mathrm{MHz}$.

the effect observed is consistent with the known characteristic of pure NBT samples composed of ferroelectric rhombohedral clusters embedded in a nonpolar tetragonal matrix. ${ }^{9}$

Dielectric measurements revealed two-phase transitions, accompanied by maxima in the temperature dependencies of relative dielectric permittivity at temperatures of $T_{p t} \sim 390$ $420 \mathrm{~K}$ and of $T_{C} \sim 530-600$ (Figs. 4 and 5). Slight increase in the $T_{p t}$ value was observed with increasing BF content: $5 \mathrm{~K}$ for compositions with $x=0.06,2 \mathrm{~K}$ for compositions with $x=0.08$ and $12 \mathrm{~K}$ for compositions with $x=0.10$. Slight increase of $\sim 20 \mathrm{~K}$ in the $T_{C}$ value was also revealed with increasing $\mathrm{BF}$ content in the samples with $x=0.06$ and $x=0.10$. Addition of $\mathrm{KCl}$ leads to decrease in $T_{p t}$ value from 422 to $402 \mathrm{~K}$ for the samples with $x=0.06, y=0.10$ and from 410 to $398 \mathrm{~K}$ for the samples with $x=0.10, y=0.10$. The phase transitions at 390-420 K reveal relaxor behavior similar to that observed in pure BNT samples and attributed to the presence of ferroelectric clusters in a nonpolar matrix. ${ }^{9}$ It should be noted that at temperatures higher than $700 \mathrm{~K}$ additional anomalies with strong frequency relaxation were revealed that may be stimulated by the presence of vacancies in oxygen sublattice resulting from the cation deficiency in the A-sublattice. ${ }^{27}$

At the room temperature electroconductivity $\sigma_{r t}$ of the samples decreases with $y$ increasing. However, at high temperature $\sim 950 \mathrm{~K} \sigma_{r t}$ value increases with $\mathrm{BF}$ content increasing. At $300 \mathrm{~K}$ the $\sigma_{r t}$ value of the $\mathrm{KCl}$-modified samples with $x=0.06$ and $y=0.10$ is higher $\left(\sigma_{r t}=\right.$ $2.3 \cdot 10^{-8} \mathrm{~S} / \mathrm{cm}$ at $\left.1 \mathrm{kHz}\right)$ than $\sigma_{r t}$ value of initial samples $\left(\sigma_{r t}=1.0 \cdot 10^{-8} \mathrm{~S} / \mathrm{cm}\right)$, however, the $\sigma_{r t}$ value of the KCl-modified samples with $x=0.10$ and $y=0.10$ is lower than $\sigma_{r t}$ of initial samples $\left(\sigma_{r t}=1.9 \cdot 10^{-8} \mathrm{~S} / \mathrm{cm}\right.$ and $2.4 \cdot 10^{-8} \mathrm{~S} / \mathrm{cm}$, correspondingly).

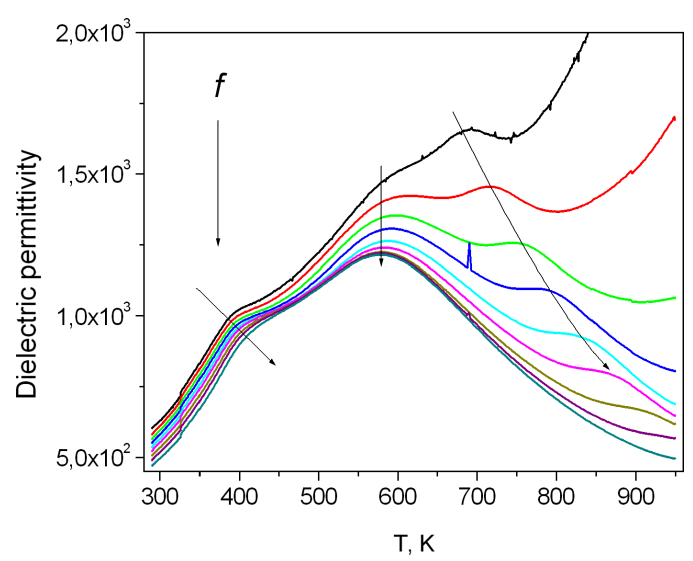

(a)

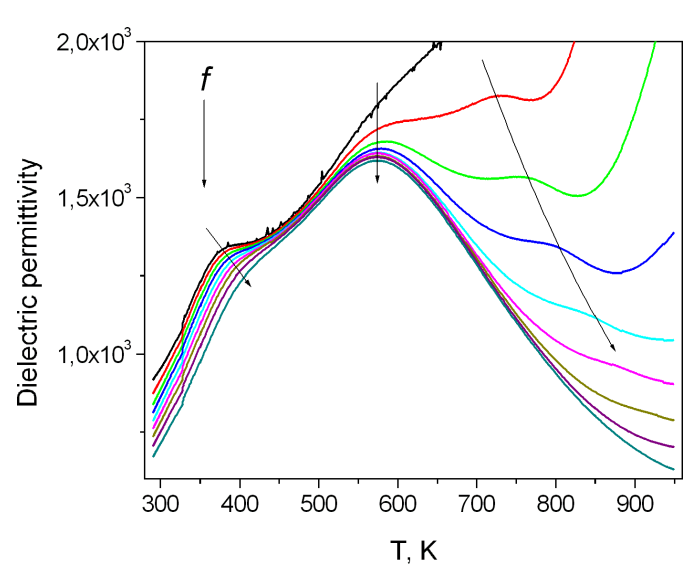

(b)

Fig. 5. Temperature dependences of dielectric permittivity $\varepsilon(T)$ of the samples $(1-y)\left[(1-x)\left(\mathrm{Na}_{0.5} \mathrm{Bi}_{0.5}\right) \mathrm{TiO}_{3}-x\left(\mathrm{~K}_{0.5} \mathrm{Na}_{0.5}\right) \mathrm{NbO}_{3}\right]-$ $y \mathrm{BiFeO}_{3}$ with $x=0.06, y=0.10(\mathrm{a}, \mathrm{b})$ with 0 (a) and $5 \mathrm{wt} . \% \mathrm{KCl}$ (b) sintered at $1443 \mathrm{~K}$ (a) and at $1453 \mathrm{~K}$ (b) measured at frequencies $f=100 \mathrm{~Hz}, 300 \mathrm{~Hz}, 1 \mathrm{kHz}, 3 \mathrm{kHz}, 10 \mathrm{kHz}, 30 \mathrm{kHz}, 100 \mathrm{kHz}$, $300 \mathrm{kHz}$ and $1 \mathrm{MHz}$.

At the room temperature, the highest values of the dielectric permittivity $\varepsilon_{r t} \sim 750-1100$ (at $1 \mathrm{kHz}$ ) were revealed in the samples with $y=0.05$. And the $\varepsilon_{r t}$ values of the $\mathrm{KCl}-$ modified samples with $x=0.06,0.10$, and $y=0.10(\sim 850$ and 800) are higher than $\varepsilon_{r t}$ in unmodified samples. These data allow us to expect an improvement of piezoelectric properties just in compositions modified by small amounts $(\sim 5 \mathrm{~mol} \%)$ of the $\mathrm{BF}$ additives and in the $\mathrm{KCl}$-modified samples taking into account the known correlation between piezoelectric coefficient $d_{33}$ and the room-temperature dielectric permittivity $\varepsilon_{r t}$ value observed that may serve as an indication on possible enhancement of piezoelectric properties. ${ }^{28,29}$

\section{Conclusions}

The phase formation, structure, microstructure and dielectric properties of ceramic samples $(1-y)\left[(1-x)\left(\mathrm{Na}_{0.5} \mathrm{Bi}_{0.5}\right)\right.$ $\left.\mathrm{TiO}_{3}-x\left(\mathrm{~K}_{0.5} \mathrm{Na}_{0.5}\right) \mathrm{NbO}_{3}\right]-y \mathrm{BiFeO}_{3}$ additionally modified by 
the $\mathrm{KCl}$ additives have been studied. Single-phase solid solutions characterized by perovskite structure were prepared by the solid-state reaction method. The ceramics were shown to characterize the optimal microstructure with dense packed cubic grains. Dielectric measurements revealed two-phase transitions, accompanied by maxima in the temperature dependencies of relative dielectric permittivity at temperatures of $\sim 390-420 \mathrm{~K}$ and $\sim 530-600 \mathrm{~K}$. It was proved that increase in the $\mathrm{BF}$ content led to slight increase in the Curie temperature value. Modification of compositions by small amounts of the $\mathrm{BF}$ and $\mathrm{KCl}$ additives leads to improvement of dielectric parameters favoring to the piezoelectric properties enhancement.

\section{Acknowledgment}

The work was supported by the Russian Foundation for Basic Research (Grant 15-03-03269).

\section{References}

${ }^{1}$ E. Cross, Materials science-Lead-free at last, Nature 432, 24 (2004).

${ }^{2}$ Y. Saito, H. Takao, T. Tani, T. Nonoyama, K. Takatori, T. Homma, T. Nagaya and M. Nakamura, Lead-free piezoceramics, Nature 432, 84 (2004).

${ }^{3}$ T. Takenaka, H. Nagata, Y. Hiruma, Y. Yoshii and K. Matumoto, Lead-free piezoelectric ceramics based on perovskite structure, $J$. Electroceram. 19, 259 (2007).

${ }^{4}$ S. J. Zhang, R. Xia and R. T. Shrout, Lead-free piezoelectric ceramics: Alternatives for PZT? J. Electroceram. 19, 251 (2007).

${ }^{5}$ T. Takenaka, H. Nagata and Y. Hiruma, Current developments and prospective of lead-free piezoelectric ceramics, Jpn. J. Appl. Phys. 47, 3787 (2008).

${ }^{6}$ J. Rodel, W. Jo, K. Seifert, E. M. Anton, T. Granzow and D. Damjanovic, Perspective on the development of lead-free piezoceramics, J. Am. Ceram. Soc. 92, 1153 (2009).

${ }^{7}$ P. K. Panda, Review: Environmental friendly lead-free piezoelectric materials, J. Mater. Sci. 44, 5049 (2009).

${ }^{8}$ D. Damjanovich, N. Klein, J. Li and V. Porokhonskyy, What can be expected from lead-free piezoelectric materials? Funct. Mater. Lett. 3, 5 (2010).

${ }^{9}$ V. V. Shvartsman and D. C. Lupascu, Lead-free relaxor ferroelectrics, J. Am. Ceram. Soc. 95, 1 (2012).

${ }^{10}$ G. A. Smolenskii, V. A. Isupov, A. I. Agranovskaya and N. N. Krainik, New ferroelectrics of complex composition IV, Sov. Phys. Solid State 2, 2651 (1961).

${ }^{11}$ S. B. Vakhrushev, V. A. Isupov, B. E. Kvyatkovsky, N. M. Okuneva, I. P. Pronin, G. A. Smolensky and P. P. Syrnikov, Phase transitions and soft modes in sodium bismuth titanate, Ferroelectrics 63, 153 (1985).

${ }^{12}$ Yu. N. Venevtsev, E. D. Politova and S. A. Ivanov, Ferro- and Antiferroelectrics of Barium Titanium Oxide Family (Chemistry, Moscow, 1985), p. 256.

${ }^{13}$ G. O. Jones and P. A. Thomas, Investigation of the structure and phase transitions in the novel a-site substituted distorted perovskite compound $\mathrm{Na}_{0.5} \mathrm{Bi}_{0.5} \mathrm{TiO}_{3}$, Acta Crystallogr. Sect. B 58, 168 (2002).
${ }^{14}$ Y. Hiruma, H. Nagata and T. Takenaka, Thermal depoling process and piezoelectric properties of bismuth sodium titanate ceramics, J. Appl. Phys. 105, 084112 (2009).

${ }^{15}$ Y. H. Zhen and J. F. Li, Normal sintering of $(\mathrm{K}, \mathrm{Na}) \mathrm{NbO}_{3}$-based ceramics: Influence of sintering temperature on densification, microstructure, and electrical properties, J. Am. Ceram. Soc. 89, 3669 (2006).

${ }^{16} \mathrm{~K}$. Wang and J. F. Li, (K,Na) $\mathrm{NbO}_{3}$-based lead-free piezoceramics: Phase transition, sintering and property enhancement, J. Adv. Ceram. 1, 24 (2012).

${ }^{17}$ J. F. Li, K. Wang, F. Y. Zhu, L. Q. Cheng and F. Z. Yao, (K,Na) $\mathrm{NbO}_{3}$-based lead-free piezoceramics: Fundamental aspects, processing technologies, and remaining challenges, J. Am. Ceram. Soc. 96, 3677 (2013).

${ }^{18}$ G. M. Kaleva, A. V. Mosunov, S. Yu. Stefanovich and E. D. Politova, Preparation and dielectric properties of potassium sodium niobate, Inorg. Mater. 49, 826 (2013).

${ }^{19}$ H. Nagata, M. Yoshida, Y. Makiuchi and T. Takenaka, Large piezoelectric constant and high curie temperature of lead-free piezoelectric ceramic ternary system based on bismuth sodium titanate-bismuth potassium titanate-barium titanate near the morphotropic phase boundary, Jpn. J. Appl. Phys. 42(Pt 1), 7401 (2003).

${ }^{20} \mathrm{M}$. E. Ringgaard and T. Wurlitzer, Lead-free piezoceramics based on alkali niobates, J. Eur. Ceram. Soc. 25, 2701 (2005).

${ }^{21}$ R. Zuo, X. Fang and C. Ye, Phase Structures and Electrical Properties of New Lead-Free $\left(\mathrm{Na}_{0.5} \mathrm{~K}_{0.5}\right) \mathrm{NbO}_{3}-\left(\mathrm{Bi}_{0.5} \mathrm{Na}_{0.5}\right) \mathrm{TiO}_{3}$ Ceramics, Appl. Phys. Lett. 90, 092904 (2007).

${ }^{22}$ A. B. Kounga, S. T. Zhang, W. Jo, T. Granzow and J. Rodel, Morphotropic phase boundary in $(1-\mathrm{x}) \mathrm{Bi}_{0.5} \mathrm{Na}_{0.5} \mathrm{TiO}_{3}-$ $\mathrm{xK}_{0.5} \mathrm{Na}_{0.5} \mathrm{NbO}_{3}$ lead-free piezoceramics, Appl. Phys. Lett. 92, 222902 (2008).

${ }^{23}$ D. Q. Xiao, D. M. Lin, J. G. Zhu and P. Yu, Studies on new systems of BNT-based lead-free piezoelectric ceramics, J. Electroceram. 21, 34 (2008).

${ }^{24}$ P. Laoratanakul, R. Yimnirun and S. Wongsaenmai, Phase formation and dielectric properties of bismuth sodium titanate-potassium sodium niobate ceramics, Curr. Appl. Phys. 11, 161 (2011).

${ }^{25}$ A. Hussain, C. W. Ahn, A. Ullah, J. S. Lee and I. W. Kim, Dielectric, ferroelectric and fied-induced strain behavior of $\mathrm{K}_{0.5} \mathrm{Na}_{0.5} \mathrm{NbO}_{3}$-modified $\mathrm{Bi}_{0.5}\left(\mathrm{Na}_{0.78} \mathrm{~K}_{0.22}\right)_{0.5} \mathrm{TiO}_{3} \quad$ lead-free ceramics, Ceram. Int. 38, 4143 (2012).

${ }^{26}$ E. D. Politova, V. S. Akinfiev, G. M. Kaleva, A. V. Mosunov, S. Yu. Stefanovich and A. H. Segalla, Effects of $\mathrm{KCl}$ additives on structure, phase transitions and dielectric properties of $0.36 \mathrm{BiScO}_{3}-0.64 \mathrm{PbTiO}_{3}$ Ceramics, Ferroelectrics 464, 399 (2014).

${ }^{27}$ E. D. Politova, G. M. Kaleva, A. V. Mosunov, A. H. Segalla and J. Zeng, Phase transitions, dielectric and piezoelectric properties of $\mathrm{BiScO}_{3}-\mathrm{PbTiO}_{3}$ ceramic solid solutions, Key Eng. Mater. 512515, 1363 (2012).

${ }^{28}$ J. L. Hyeong and Z. H. Shujun, Perovskite lead-free piezoelectric ceramics, Lead-Free Piezoelectrics, eds. S. Priya and S. Nahm (Springer, New York, 2012), pp. 291-309.

${ }^{29}$ A. H. Segalla, S. S. Nersesov, G. M. Kaleva and E. D. Politova, Ways of improving functional parameters of high-temperature ferroelectric/piezoelectric ceramics based on $\mathrm{BiScO}_{3}-\mathrm{PbTiO}_{3}$ solid solutions, Inorg. Mater. 50, 606 (2014). 